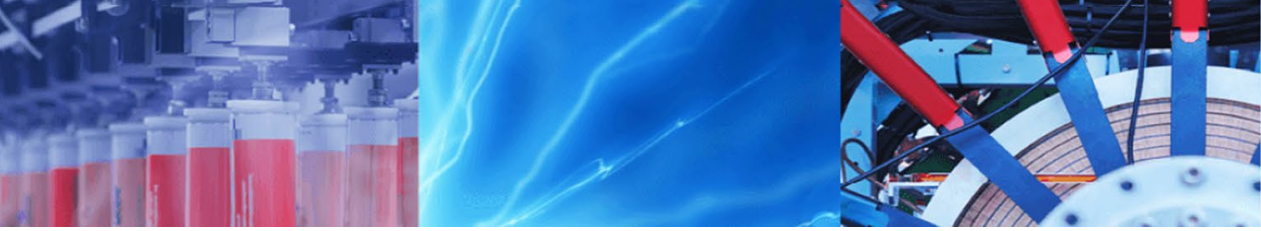

Research Article

\title{
Feedback linearization associated to a sliding mode controller for an operating with unity power factor of induction motor fed by matrix converter
}

\author{
Abdelhakim Dendouga ${ }^{1}$ (1) \\ Received: 11 October 2019 / Accepted: 2 April 2020 / Published online: 11 April 2020 \\ (c) Springer Nature Switzerland AG 2020
}

\begin{abstract}
In order to achieve a high performance and to ensure an operation with a unit power factor with respect to imposed reference signals, the input-output feedback linearization technique with a sliding mode controller was proposed to control the induction motor fed by matrix converter drive system. In addition, the direct space vector modulation strategy is adopted to control the matrix converter to minimize the switching losses. On the other hand, a damped input filter has been used to reduce the harmonic total distortion rate injected to the grid. Moreover, the topology and the optimization method for parameter calculation of the input filter are also clarified. The robustness of the proposed control strategy for the drive system was tested and validated by a simulation study.
\end{abstract}

Keywords Damped RLC input filter · Direct space vector modulation · Feedback linearization · Matrix converter fed induction motor drive system · Sliding mode controller · Unity power factor operation

\section{Introduction}

In recent decades and thanks to the developments in the fields of microelectronics and computer technology, the matrix converter $(\mathrm{MC})$ is becoming a more attractive topic for several researchers, because of its competitive advantages compared to conventional AC-DC-AC (back-to-back) converters such as: compact size, bidirectional power flow, power adjustment capability, unity power factor operation, does not need a DC-link capacitor [1-5]. The Venturini and space vector modulation (SVM) methods are usually used in the literature to solve the MC control problem. The Venturini method presents a low harmonic rate. However, reduced switching losses is the major advantage of the SVM method [6-8].

The use of a passive filter at the input of MC is necessary to avoid the injection of current harmonics into the grid. In this context, several types of the input filter to solve the filtering problem in the MC have been proposed. Consequently, the inductive capacitive filter with a damping resistor considered a suitable solution thanks to its satisfactory performance provided [9-11].

Recently, several methods have emerged for the control of induction motor fed by MC. The field-oriented control (FOC) allows a natural decoupling between the speed and flux amplitude. However, the parameter variations and the high operation speed cause loss decoupling [12-14].

The direct torque control (DTC) has found is an interesting solution in terms to reduce the dependence on parameters $[15,16]$. In spite of its advantages, the variation of stator resistor due to the temperature degrades the performance of this control method $[17,18]$. Moreover, an improved model predictive control method (MPC) is proposed for the IM drives fed by an MC $[19,20]$. Although the vector selected from MPC is more accurate and effective than the one which selected for DTC, the steady state

$\triangle$ Abdelhakim Dendouga, hakimdendouga@yahoo.fr | ${ }^{1}$ I3CUB Research Laboratory, Department of Electrical Engineering, University of Biskra, Biskra, Algeria. 
performance is still not satisfactory and inferior to that of FOC. The nonlinear control is another alternative strategy to ensure an excellent decoupling for induction motor while ensuring a perfect linearization some is the profiles of the reference trajectories imposed on the system [21, 22]. The authors in [22] propose a second order nonlinear robust auto disturbance rejection controller (ADRC) for control of IM fed by MC. This study presents an interesting initiative for nonlinear approach application to control the considered drive system.

In this work, the input-output feedback linearization technique is used with a sliding mode controller to generate the reference voltages for a MC controlled by direct SVM (DSVM) strategy to achieve a high performance and to ensure an operation with a unit power factor of IM drive system. Moreover, the design procedure of the input filter with damping resistor concerning the transfer function that describes its topology as well the optimal method of parameter selection have been clearly presented. In order to evaluate the robustness of the proposed drive system a simulation study has been carried out.

\section{Control strategy design}

\subsection{Induction motor model}

The model of IM in a fixed reference frame $(\alpha-\beta)$, is given by

$\dot{x}=f(x)+g u$

$y=h(x)$

where:

$$
\begin{aligned}
& x=\left[\begin{array}{lllll}
i_{s \alpha} & i_{s \beta} & \varphi_{r \alpha} & \varphi_{r \beta} & \omega
\end{array}\right] u=\left[\begin{array}{c}
\mathrm{v}_{s \alpha} \\
\mathrm{v}_{s \beta}
\end{array}\right] ; \\
& f(x)=\left[\begin{array}{l}
-\gamma i_{s \alpha}+\frac{K}{T_{r}} \varphi_{r \alpha}+K n_{p} \omega \varphi_{r \beta} \\
-\gamma i_{s \beta}+\frac{K}{T_{r}} \varphi_{r \beta}-K n_{p} \omega \varphi_{r \alpha} \\
\frac{L_{m}}{T_{r}} i_{s \alpha}-\frac{1}{T_{r}} \varphi_{r \alpha}-n_{p} \omega \varphi_{r \beta} \\
\frac{L_{m}}{T_{r}} i_{s \beta}-\frac{1}{T_{r}} \varphi_{r \beta}+n_{p} \omega \varphi_{r \alpha} \\
\frac{n_{p} L_{m}}{J L_{r}}\left(\varphi_{r \alpha} i_{s \beta}-\varphi_{r \beta} i_{s \alpha}\right)-\frac{1}{J}\left(B \omega+T_{L}\right)
\end{array}\right] \\
& g=\left[\begin{array}{cc}
\frac{1}{\sigma L_{s}} & 0 \\
0 & \frac{1}{\sigma L_{s}} \\
0 & 0 \\
0 & 0 \\
0 & 0
\end{array}\right] \text {. }
\end{aligned}
$$

$$
T_{r}=\frac{L_{r}}{R_{r}}, \sigma=1-\frac{L_{m}}{L_{s} L_{r}}, \gamma=\frac{1}{\sigma L_{s}}\left(R_{s}+\frac{L_{m}^{2}}{L_{r} T_{r}}\right), K=\frac{L_{m}}{\sigma L_{s} L_{r}}
$$

\subsection{Feedback linearization}

The torque $\left(T_{e}\right)$ and the norm of the rotor flux $\left(\varphi_{r \alpha}^{2}+\varphi_{r \beta}^{2}\right)$ are defined as the outputs of the system [23], [24].

$h(x)=\left[\begin{array}{l}h_{1}(x) \\ h 2(x)\end{array}\right]=\left[\begin{array}{c}T_{e} \\ \varphi_{r}^{2}\end{array}\right]=\left[\begin{array}{l}\frac{n_{p} L_{m}}{L_{r}}\left(\varphi_{r \alpha} i_{s \beta}-\varphi_{r \beta} i_{s \alpha}\right) \\ \varphi_{r \alpha}^{2}+\varphi_{r \beta}^{2}\end{array}\right]$

The Lie derivatives of the outputs are given by:

- For the first output: $y_{1}=h_{1}(x)=T_{e}$

$\dot{y}_{1}=\dot{h}_{1}(x)=L_{f} h_{1}(x)+L_{g_{1}} h_{1}(x) v_{s \alpha}+L_{g_{2}} h_{1}(x) v_{s \beta}$

where

$$
\left\{\begin{array}{l}
L_{f} h_{1}(x)=\frac{n_{p} L_{m}}{L_{r}}\left[\left(\gamma+\frac{1}{T_{r}}\right)\left(\varphi_{r \beta} i_{s \alpha}-\varphi_{r \alpha} i_{s \beta}\right)\right. \\
\left.-K n_{p} \omega\left(\varphi_{r \alpha}^{2}+\varphi_{r \beta}^{2}\right)-n_{p} \omega\left(\varphi_{r \alpha} i_{s \alpha}+\varphi_{r \beta} i_{s \beta}\right)\right] \\
L_{g_{1}} h_{1}(x)=\frac{\partial h_{1}(x)}{\partial x_{i}} g_{1}=-\frac{n_{p} L_{m}}{\sigma L_{r} L_{s}} \varphi_{r \beta} \\
L_{g_{2}} h_{1}(x)=\frac{\partial h_{1}(x)}{\partial x_{i}} g_{2}=\frac{n_{p} L_{m}}{\sigma L_{r} L_{s}} \varphi_{r \alpha}
\end{array}\right.
$$

The relative degree related to first output is: $r_{1}=1$.

- For the second output: $y_{2}=h_{2}(x)=\varphi_{r}^{2}$

$$
\left\{\begin{aligned}
\dot{y}_{2}= & \dot{h}_{2}(x)=L_{f} h_{2}(x) \\
\ddot{y}_{2}= & \ddot{h}_{2}(x)=L_{f}^{2} h_{2}(x)+L_{g_{1}}\left(L_{f} h_{2}(x)\right) v_{s \alpha} \\
& +L_{g_{2}}\left(L_{f} h_{2}(x)\right) v_{s \beta}
\end{aligned}\right.
$$

where

$$
\left\{\begin{array}{l}
L_{f} h_{2}(x)=\frac{2 L_{m}}{T_{r}}\left(\varphi_{r \alpha} i_{s \alpha}+\varphi_{r \beta} i_{s \beta}\right)-\frac{2}{T_{r}}\left(\varphi_{r \alpha}^{2}+\varphi_{r \beta}^{2}\right) \\
L_{f}^{2} h_{2}(x)=\frac{-2 L_{m}}{T_{r}}\left[\left(\gamma+\frac{3}{T_{r}}\right)\left(\varphi_{r \alpha} i_{s \alpha}+\varphi_{r \beta} i_{s \beta}\right)+n_{p} \omega\left(\varphi_{r \beta} i_{s \alpha}-\varphi_{r \alpha} i_{s \beta}\right)\right. \\
\left.+\left(\frac{2 K L_{m}+4}{T_{r}^{2}}\right)\left(\varphi_{r \alpha}^{2}+\varphi_{r \beta}^{2}\right)+\frac{2 L_{m}^{2}}{T_{r}^{2}}\left(i_{r \alpha}^{2}+i_{r \beta}^{2}\right)\right] \\
L_{g_{1}}\left(L_{f} h_{2}(x)\right)=\frac{\partial\left(L_{f} h_{2}(x)\right)}{\partial x_{i}} g_{1}=\frac{2 L_{m}}{\sigma L_{s} T_{r}} \varphi_{r \alpha} \\
L_{g_{2}}\left(L_{f} h_{2}(x)\right)=\frac{\partial\left(L_{f} h_{2}(x)\right)}{\partial x_{i}} g_{2}=\frac{2 L_{m}}{\sigma L_{s} T_{r}} \varphi_{r \beta}
\end{array}\right.
$$

In this case: $r_{2}=1$. The total relative degree is $r=r_{1}+r_{2}=3$, in this case, the full linearization is not 
achieved. To solve this problem the following change of variables is necessary [25]:

$\left\{\begin{array}{l}z_{1}=y_{1} \\ z_{2}=y_{2} \\ z_{3}=\dot{z}_{2}=L_{f} h_{2}(x) \\ z_{4}=\arctan \left(\frac{\varphi_{r \beta}}{\varphi_{r \alpha}}\right) \\ z_{5}=\omega\end{array}\right.$

The derivation of the system of Eqs. (7) is:

$$
\begin{aligned}
& \left\{\begin{array}{l}
\dot{z}_{1}=v_{1} \\
\dot{z}_{2}=z_{3} \\
\dot{z}_{3}=v_{2} \\
\dot{z}_{4}=n_{p} \omega+\frac{R_{r} z_{1}}{n_{p} z_{2}} \\
\dot{z}_{5}=\frac{1}{j}\left(z_{1}-T_{L}-f z_{5}\right)
\end{array}\right. \\
& v_{1} \text { and } v_{2} \text { of system are defined by } \\
& {\left[\begin{array}{l}
v_{1} \\
v_{2}
\end{array}\right]=\left[\begin{array}{l}
L_{f} h_{1} \\
L_{f}^{2} h_{2}
\end{array}\right]+D(x)\left[\begin{array}{l}
v_{s \alpha} \\
v_{s \beta}
\end{array}\right]}
\end{aligned}
$$

where $D(x)$ is the decoupled matrix defined as

$$
D(x)=\left[\begin{array}{ll}
L_{g_{1}} h_{1} & L_{g_{2}} h_{1} \\
L_{g_{1}} L_{f} h_{2} & L_{g_{2}} L_{f} h_{2}
\end{array}\right]=\left[\begin{array}{ll}
-\frac{n_{p} L_{m}}{\sigma L_{L} L_{s}} \varphi_{r \beta} & \frac{n_{p} L_{m}}{\sigma L_{L_{1}} L_{s}} \varphi_{r \alpha} \\
\frac{2 L_{m}}{\sigma L_{s} T_{r}} \varphi_{r \alpha} & \frac{2 L_{m}}{\sigma L_{s} T_{r}} \varphi_{r \beta}
\end{array}\right]
$$

Since $\operatorname{det}(D(x)) \neq 0, D(x)$ is nonsingular everywhere in $\omega$. After the arranging of Eq. (9) we obtain

$\left[\begin{array}{l}v_{s \alpha} \\ v_{s \beta}\end{array}\right]=D^{-1}(x)\left[\begin{array}{l}v_{1}-L_{f} h_{1} \\ v_{2}-L_{f}^{2} h_{2}\end{array}\right]$

The input signals $v_{1}$ and $v_{2}$ in (11) are designed as [25]

$\left\{\begin{array}{r}v_{1}=k_{11}\left(z_{1 \text { ref }}-z\right)+\dot{z}_{\text {ref }} \\ v_{2}=k_{21}\left(z_{2 \text { ref }}-z_{2}\right)+k_{22}\left(\dot{z}_{2 \text { ref }}-\dot{z}_{2}\right)+\ddot{z}_{2 \text { ref }}\end{array}\right.$

where $k_{11}, k_{21}$ and $k_{22}$ are positive factors parameters can be calculated by imposing a dynamics on the error according to

$$
\left\{\begin{array}{l}
k_{11} e_{1}+\dot{e}_{1}=0 \\
k_{21} e_{2}+k_{22} \dot{e}_{2}+\ddot{e}_{2}=0
\end{array}\right.
$$

where $e_{1}=\left(z_{1 \text { ref }}-z_{1}\right), e_{2}=\left(z_{2 \text { ref }}-z_{2}\right)$

The above dynamics will be stable if the two polynomials of $e_{1}$ and $e_{2}$ have their roots on the left side of complex plan $[25,26]$.

\subsection{Sliding mode controller design}

The control objective in this section is to design a sliding-mode speed controller for the IM system. In order to guarantee an excellent speed $\left(z_{5}=\omega\right)$ tracking with respect to the variation of its reference, a SMC is designed taking the place of conventional PI controller, as follows [27]:

$z_{1 \text { ref }}=\left(z_{1 \text { ref }}\right)_{e q}+\left(z_{1 \text { ref }}\right)_{n}$

For the speed, the slip surface is selected as

$S\left(z_{5}\right)=e\left(z_{5}\right)=z_{5 r e f}-z_{5}$

its time derivate is expressed by

$\dot{S}\left(z_{5}\right)=\dot{z}_{5 \text { ref }}-\dot{z}_{5}$

Under sliding mode condition $\left(\dot{S}\left(z_{5}\right)=0\right)$, and the equivalent component of the reference torque is given by

$\left(z_{1 \text { ref }}\right)_{e q}=\dot{z}_{5 \text { ref }}+\frac{1}{J}\left(f z_{5 \text { ref }}+T_{L}\right)$

In order to minimize the chattering phenomenon (high frequency oscillations) due to the discontinuous nature of the SMC, a smooth function is used for the nonlinear component. In our case, we take the following function.

$\left(z_{1 r e f}\right)_{n}=k_{\omega} \frac{S\left(z_{5}\right)}{\left|S\left(z_{5}\right)\right|+\varepsilon_{\omega}}$

where $k_{\omega^{\prime}} \varepsilon_{\omega}$ are positive constants.

\section{Direct space vector modulation}

From 27 possible configurations of the $M C$, there are only 21 configurations containing 18 stationary vectors (from \pm 1 to \pm 9 ) and 3 null vectors, can be used by the DSVM technique to form the output voltage and the input current for the MC (Fig. 1). The representation of the 18 stationary vectors for the voltage and for the current in the fixed frame of reference $(\alpha, \beta)$, makes it possible to form two regular hexagons, each two consecutive vectors forming one sector. In this context, in each modulation period four stationary vectors are selected by the DSVM technique to calculate the switching times for MC. Moreover, the modulation period is completed by the application of the null vector. The expressions that allow the determination of switching times are given by $[5,7,12]$ :

$\delta_{1}=\frac{2}{\sqrt{3}} q \sin \left[\alpha_{o}-\left(k_{v}-1\right) \frac{\pi}{3}\right] \sin \left[\frac{\pi}{6}-\left(\alpha_{i}-\left(k_{i}-1\right) \frac{\pi}{3}\right)\right]$

$\delta_{2}=\frac{2}{\sqrt{3}} q \sin \left[\alpha_{o}-\left(k_{v}-1\right) \frac{\pi}{3}\right] \sin \left[\frac{\pi}{6}+\left(\alpha_{i}-\left(k_{i}-1\right) \frac{\pi}{3}\right)\right]$ 


$$
\begin{aligned}
& \delta_{3}=\frac{2}{\sqrt{3}} q \sin \left[k_{v} \frac{\pi}{3}-\alpha_{o}\right] \sin \left[\frac{\pi}{6}-\left(\alpha_{i}-\left(k_{i}-1\right) \frac{\pi}{3}\right)\right] \\
& \delta_{4}=\frac{2}{\sqrt{3}} q \sin \left[k_{v} \frac{\pi}{3}-\alpha_{o}\right] \sin \left[\frac{\pi}{6}+\left(\alpha_{i}-\left(k_{i}-1\right) \frac{\pi}{3}\right)\right] \\
& \delta_{0}=1-\left(\delta_{1}+\delta_{2}+\delta_{3}+\delta_{4}\right)
\end{aligned}
$$

where $q=V_{o} / V_{i}$ is the voltage ratio; $a_{o}$ and $a_{i}$ are the phase angles of the output voltage and input current vectors, respectively; $k_{v} k_{i}$ are the sector number of output voltage and input current vectors.

\section{Damped RLC input filter design}

Figure 2 shows a more suitable approach for damped input filter design, which uses a resistor connected in parallel with the capacitor of input filter to increase the damping factor of the LC filter. In order to improve the current waveform at the input of $\mathrm{MC}$, and therefore to reduce harmonic injection to the grid [10,11]. The voltage and current transfer function are given by Eqs. (24) and (25).

$V_{A}(s)=\frac{R_{d} \cdot V_{g A}(s)-R_{d} \cdot\left(L_{f} \cdot s+R_{f}\right) I_{A}(s)}{R_{d} \cdot L_{f} \cdot C_{f} \cdot s^{2}+\left(R_{d} \cdot R_{f} \cdot C_{f}+L_{f}\right) \cdot s+\left(R_{d}+R_{f}\right)}$

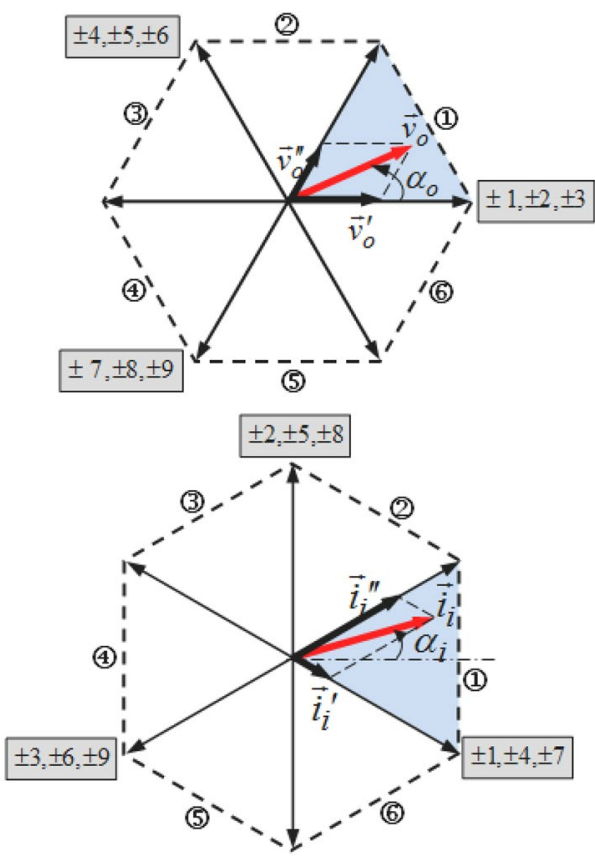

Fig. 1 Output voltage and input current space vectors

$$
I_{g A}(s)=\frac{\left(R_{d} \cdot C_{f} \cdot s+1\right) \cdot V_{g A}(s)+R_{d} \cdot I_{A}(s)}{R_{d} \cdot L_{f} \cdot C_{f} \cdot s^{2}+\left(R_{d} \cdot R_{f} \cdot C_{f}+L_{f}\right) \cdot s+\left(R_{d}+R_{f}\right)}
$$

The parameter selection of $C$ and $L$ must satisfy the following condition:

- $10 f_{i}<\frac{1}{2 \pi \sqrt{L_{f} C_{f}}}<10 f_{s} f_{i}$ the input supply frequency and $f_{s}$ is the switching frequency;

- Considering that the value of Rd sufficiently large and $R f$ is usually few ohms. The characteristic frequency $\omega_{n}$ and damping factor $\zeta$ can be given by

$\omega_{n}=\frac{1}{\sqrt{L_{f} C_{f}}}, \xi=\frac{1}{2 R_{d}} \sqrt{\frac{L_{f}}{C_{f}}}$

\section{Simulation and results}

The unit power factor operating of drive system and the robustness against the imposed reference of the proposed control strategy have been tested and evaluated by simulation. In this case, the robustness test involves the following operating sequences: at the beginning, the motor operates in unloaded mode. At $t=0.5 \mathrm{~s}$, a load torque is applied, then the motor is unloaded again at $t=1.5 \mathrm{~s}$. At $\mathrm{t}=2$, the speed reference takes $50 \mathrm{rd} / \mathrm{s}$ as value, and then it is reversed at $t=2.5 \mathrm{~s}$. At time $\mathrm{t}=3 \mathrm{~s}$, the reference speed takes its initial value (100rd/s). The sequences and modes of operation are summarized in Table 1.

After the simulation using the parameters shown in "Appendix" section, we obtain the plots of speed, torque, grid voltage and current (input filter voltage and current),

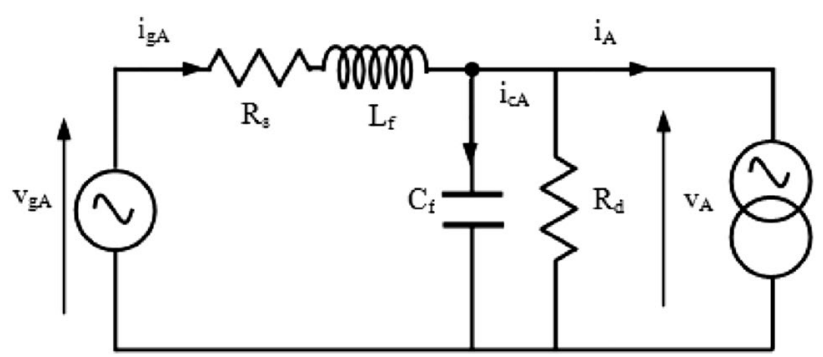

Fig. 2 Single phase RLC input filter with a damping resistor

Table 1 Operation modes

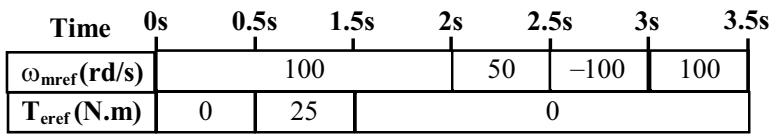




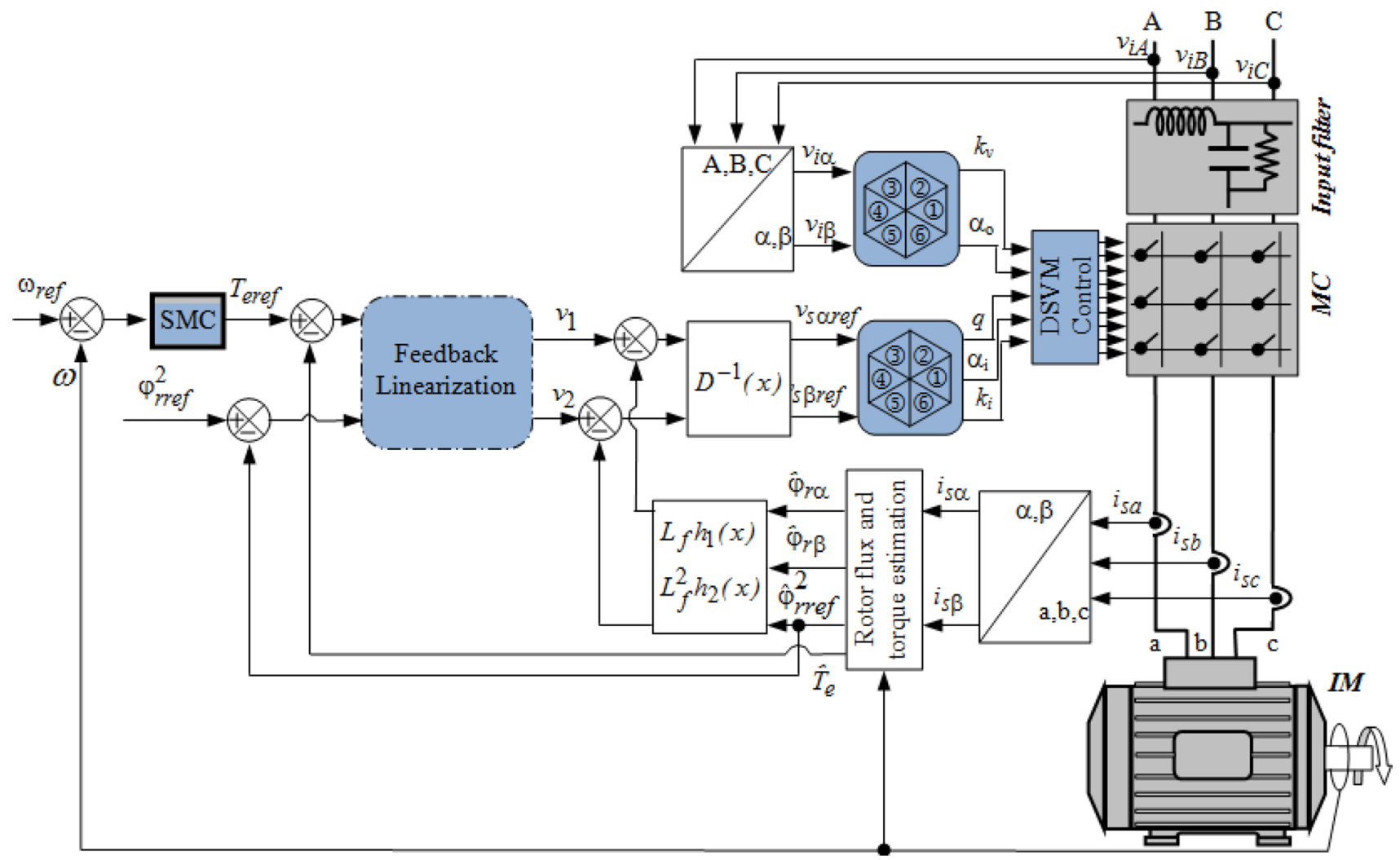

Fig. 3 Feedback linearization based on SMC for an operating with unity power factor of IM fed by MC

harmonic spectrum of grid side current, stator voltage (or output $\mathrm{mc}$ voltage). These results allow us to evaluate the robustness and performance achieved by the proposed drive system (Fig. 3).

\section{Discussions}

The simulation results shown by Fig. 4 exhibit that the dynamic performances of feedback linearization based on SMC are very acceptable in regards to the good pursuit, short response time, no steady-state errors occur.

Moreover, it is clear that the current is in phase with the voltage in the grid side, which implies that the drive system operates with a unit power factor for any mode. This operation is not possible to achieve by the use of back-toback converter. Consequently, this advantage is another strong point of the $M C[2,8]$.

In addition, a sinusoidal waveform is obtained for the current, in which has been confirmed by the harmonics spectrum ( $T H D=3.12)$. One can note also from this figure that the output MC voltage (stator phase voltage) which is formed by the chopped three-phase input voltage.

\section{Conclusion}

This work clearly confirms the high performance of the proposed drive system. This is proved by the good tracked against the reference signals, unit power factor operation, and robustness of the drive system have been ensured regarding to the external disturbances. The SMC presents a high performance, especially in terms of the good pursuit, short response time, no steady-state errors occur.

The use MC controlled by DSVM technique makes possible a flexible operation in four quadrants with bidirectional power flow, and provides operation with a unit power factor of IM drive system. This operation is not possible to achieve by the use of back-to-back converter. Consequently, this advantage is another strong point of the MC.

Moreover, the RLC input filter with a damping resistor makes it possible to obtain a near-sinusoidal waveform for the current in the grid side with a low harmonic rate.

The proposed solution is satisfactory for any high dynamic performance applications. In this context, the practical implementation of the proposed drive system is considered as a prospect for the continuation of this work. 
Fig. 4 Test by simulation of operating with an unit power factor and robustness evaluation of the proposed drive system
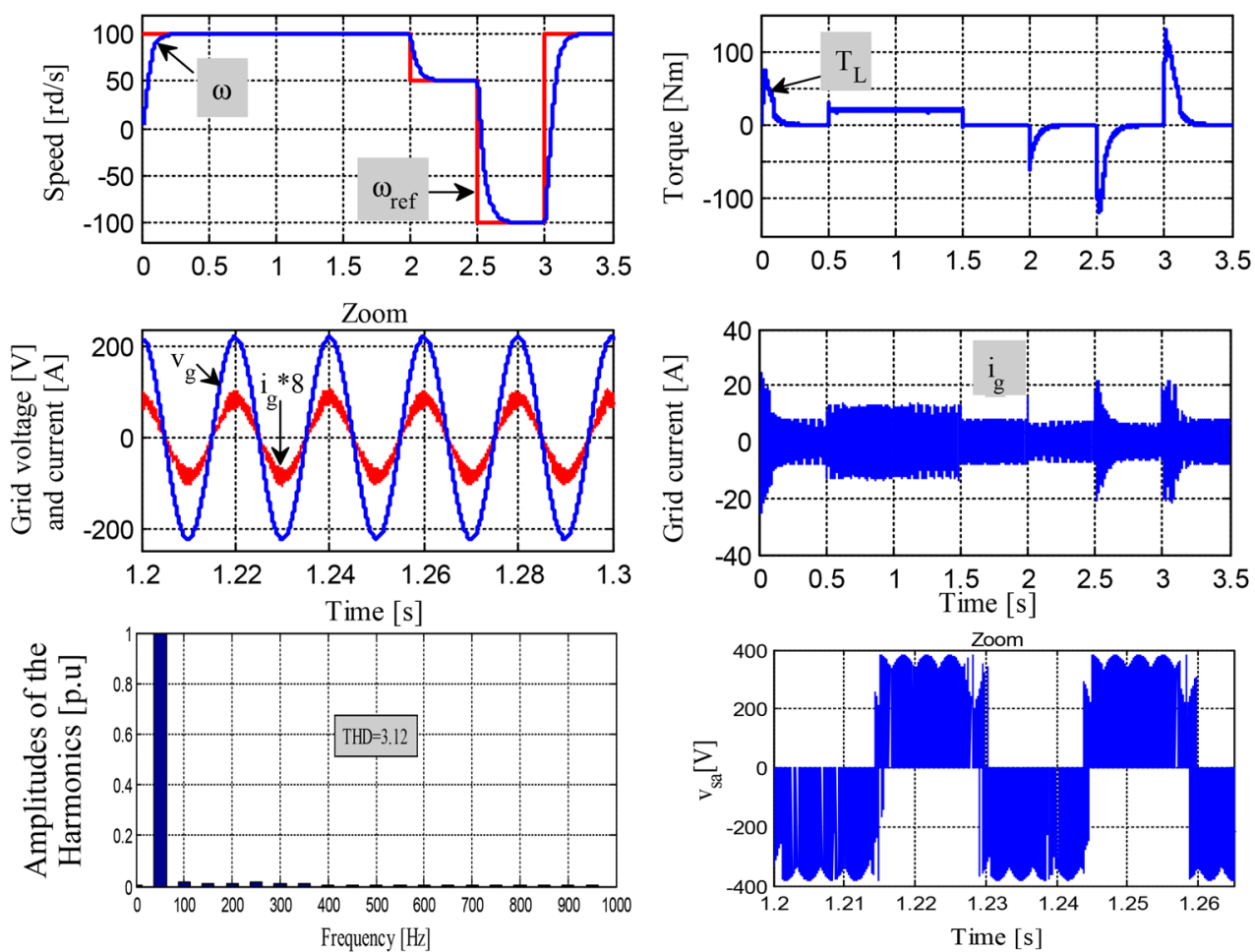

Acknowledgements The author of the work expresses thanks to the head of the reaserch laboratory I3CUB, and to all members of the laboratory for his support and encouragement.

\section{Compliance with ethical standards}

Conflict of interest The author declare that he has no conflict of interest.

\section{Appendix}

See Table 2.

- Input filter parameters:

$R_{d}=30 \Omega, \mathrm{L}_{\mathrm{f}}=700 \mu \mathrm{H}, \mathrm{C}_{\mathrm{f}}=1.1 \mu \mathrm{F}$. 
Table 2 Induction motor parameters

\begin{tabular}{lll}
\hline Symbol & Nomenclature & Value \\
\hline$R_{s}$ & Stator resistance & $2.47 \Omega$ \\
$R_{r}$ & Rotor resistance & $1.24 \Omega$ \\
$L_{s}$ & Stator inductance & $0.236 \mathrm{H}$ \\
$L_{r}$ & Rotor inductance & $0.236 \mathrm{H}$ \\
$L_{m}$ & Magnetizing inductance & $0.2269 \mathrm{H}$ \\
$J$ & total rotor inertia & $0.05 \mathrm{~kg} \mathrm{~m}^{2}$ \\
$f$ & Viscous friction coefficient & $0.00065 \mathrm{Nm} / \mathrm{rd}$ \\
$n_{p}$ & Pole pairs & 2 \\
\hline
\end{tabular}

\section{References}

1. Zhang J, Li L, Dorrell DG (2018) Control and applications of direct matrix converters: a review. Chin J Electr Eng 4(2):18-27

2. Subrata AC, Sutikno T, Jidin AZ, Jidin A (2018) Review on adjustable speed drive techniques of matrix converter fed three-phase induction machine. In: IEEE proceedings EECSI, Malang, Indonesia, pp 350-355

3. Rodriguez JJ, Caporal RM, Peralta E, Carranza O, Ortega R (2016) Optimal venturini modulation for a three-phase four-wire matrix converter. IEEE Trans Lat Am 14(2):617-623

4. Kobravi K, Iravani R, Kojori HA (2012) A review and implementation of matrix-converter for aerospace application. In: Proceedings IEEE energy conversion congress and exposition (ECCE), Raleigh, NC, USA, pp 698-705

5. Watanabe E, Ishii S, Yamamoto E, Hara H, Kang J-K, Hava AM (2000) High performance motor drive using matrix converter. In: IEE seminar, advances in motor control, pp 1-6

6. Zhang L, Watthanasarn C, Shepherd W (1998) Analysis and comparison of the control techniques for AC-AC matrix converters. IEE Proc Electr Power Appl 145(4):284-294

7. Casadei D, Serra G, Tani A (2002) Matrix converter modulation strategies: a new general approach based on space-vector representation of the switch state. IEEE Trans Ind Electr 49(2):370-381

8. Wheeler PW, Rodrigues J, Clare JC (2002) Matrix converters: technology review. IEEE Trans Ind Electr 49(2):276-288

9. Vijayagopal M, Empringham L, de Lillo L, Tarisciotti L, Zanchetta P, Wheeler P (2015) Current control and reactive power minimization of a direct matrix converter induction motor drive with modulated model predictive control. In: Proceedings IEEE international symposium on predictive control of electric drive power electronics (PRECEDE), Valparaiso, Chile, pp 103-108

10. Wang $X$, Lin H, Feng B, Lyu Y (2012) Damping of input LC filter resonance based on virtual resistor for matrix converter. In: IEEE energy conversion congress and exposition (ECCE), Raleigh, NC, USA, pp 3910-3916

11. She $H$, Lin $H$, Wang $X$, Yue $L$ (2009) Damped input filter design of matrix converter. In: Proceedings international conference on power electronics and drive systems (PEDS), Taipei, Taiwan, pp 672-677

12. Dendouga A, Abdessemed R, Essounbouli N (2013) Robustness evaluation of vector control of induction motor fed by SVM matrix converter. In: IEEE proceedings of 3rd international conference on systems and control, TuBA.6, Algiers, Algeria

13. Zhang J, Li L, Zhang L, Dorrell DG (2017) Hysteresis band current controller based field-oriented control for an induction motor driven by a direct matrix converter. In: Proceedings 43rd annual conference of the IEEE Industrial electronics society IECON, Beijing, China, pp 4633-4638

14. Lee $\mathrm{HH}$, Nguyen HM (2006) Direct rotor-flux-oriented control method using matrix converter fed induction motor. In: IEEE proceedings, IFOST'2005, pp 309-313

15. Guo Y, Wang X, Guo Y, Deng W (2018) Speed-sensorless direct torque control scheme for matrix converter driven induction motor. J Eng 18(13):432-437

16. Peng T, Wen M, Li Z, Xu Z, Yang J (2015) An improved DTC statergy for induction motors fed by direct matrix converter. Chinese Automation Congress (CAC), Wuhan, pp 1766-1771

17. MirTN, Singh B, Bhat AH (2018) Speed-sensorless DTC of a matrix converter fed induction motor using an adaptive flux observer. IETE J Res. https://doi.org/10.1080/03772063.2018.1552206

18. Boulghasoul Z, Elbacha A, Elwarraki E, Yousfi D (2011) Speedsensorless DTC of a matrix converter fed induction motor using an adaptive flux observer. In: Proceedings IEEE international conference on multimedia computing and systems, Ouarzazate, Morocco, pp 1-6

19. Mei Y, Wang L, Huang W (2018) An improved model predictive control method for induction motor drives fed by indirect matrix converter. In: Proceedings IEEE international power electronics and application conference and exposition (PEAC), Shenzhen, China, pp 1-5

20. Vijayagopal M, Empringham L, de Lillo L, Tarisciotti L, Zanchetta $\mathrm{P}$, Wheeler $\mathrm{P}$ (2015) Current control and reactive power minimization of a direct matrix converter induction motor drive with modulated model predictive control. In: Proceedings IEEE international symposium on predictive control of electrical drives and power electronics (PRECEDE), Valparaiso, Chile, pp 103-108

21. Sun K, Huang L, Zhou D (2005) A nonlinear robust controller for matrix converter fed induction motor drives. IEEE Trans Autom Control 38:1365-1370

22. Mei $Y$, Huang L (2009) A second-order auto disturbance rejection controller for matrix converter fed induction motor drive. In: Proceedings IEEE 6th international power electronics and motion control conference, Wuhan, China, pp 1964-1967

23. Merabet A (2007) Nonlinear predictive control of induction motor drive. Doctorate thesis, University of Quebec

24. Bakhti I (2007) Different nonlinear controls of sensorless induction machine with flux and speed observers. Master thesis, University of Batna, Algeria

25. Marino R, Peresada S, Valigi P (1993) Adaptative input-output linearizing control of induction motors. IEEE Trans Autom Control 38:208-221

26. Bekhouche $L$ (2009) Input-output linearizing control by Torque and flux of induction machine. Master thesis, University of Setif, Algeria

27. Yazdanpanah R, Soltani J, Markadeh GR (2008) Nonlinear torque and stator flux controller for induction motor drive based on adaptive input-output feedback linearization and sliding mode control. Elsevier Energy Convers Manag 49:541-550

Publisher's Note Springer Nature remains neutral with regard to jurisdictional claims in published maps and institutional affiliations. 